\title{
Rock Mechanics Challenges in Underground Construction and Mining
}

\author{
P.K. Kaiser Centre for Excellence in Mining Innovation, Canada
}

B-H. Kim Geomechanics Research Centre at MIRARCO - Mining Innovation, Laurentian University, Canada

\begin{abstract}
The underground construction and mining industry are facing many geomechanics challenges. This keynote address presents an overview of some practical challenges, recent developments and some new technical opportunities. In mining, going deeper, increasing safety standards, and aiming for high productivity demands engineering to maximise value. In underground construction, geological complexities and mechanisation demand better integration of engineering to ensure ease of construction.

Lack of engineering for constructability when tunnelling in weak or brittle rock at depth often leads to unnecessary delays and extra costs. Furthermore, brittle failing rock at depth poses unique problems as stress-driven failure processes often dominate the tunnel behaviour. Such failure processes can lead to shallow unravelling or to strainbursting modes of instability that cause difficult conditions for tunnel constructors.

This paper summarises lessons learned during the construction of deep Alpine tunnels and highlights implications that are of practical importance with respect to constructability. Special attention is given to issues of rock behaviour identification and to the selection of appropriate rock properties for underground construction in brittle failing ground.
\end{abstract}

\section{Introduction}

This paper draws on experiences from major, mostly deep, mining projects and from large, deep tunnelling operations. The author's experience with brittle failing rock in deep mining, underground construction, and Alpine tunnelling was previously presented in keynote lectures: at GeoEng 2000 (Kaiser et al., 2000), summarising a decade of collaborative research work on brittle rock failure; at the Rockburst and Seismicity in Mines Symposium (Kaiser et al., 2005), introducing new means of complex data interpretation in seismically active mines; at GEAT'05 (Kaiser, 2006), focusing on experiences from deep Alpine tunnelling; and at the Asian Rock Mechanics Symposium, highlighting the impact on constructability (Kaiser, 2006). This paper also summarises some aspects of the presentation made at the Canada-U.S. Rock Mechanics Symposium (Kaiser, 2007). After a brief review of findings from these studies, recent developments and implications of practical importance are highlighted, particularly with respect to the proper design for constructability of underground excavation in brittle rock.

The two most important lessons learned from these projects are: (1) at depth, the rock is much less forgiving, and (2) costly mistakes can be made. Hence, we have to learn from them and design smarter.

Furthermore, as Leopold Müller already stated in the 1960s: "We don't know the rock mass strength. That is why we need an International Society". Almost fifty years later, rock mass strength determination is still a challenge for rock engineers. Hence, recent developments related to rock and rock mass strength determination for brittle failing rock are discussed in some detail.

\subsection{Challenges and opportunities}

Current opportunities and challenges arise from: (a) our desire to answer some questions of 21st century science (Deep Underground Science and Engineering Laboratory (DUSEL) and URLs), and (b) unprecedented growth in mining and underground construction. This growth and globalisation drives innovation in many sectors, including rock mechanics and rock engineering. 
The unique image, created for deep science to reflect "As the miner's headlamp casts light on subterranean darkness, research in deep underground laboratories illuminates many of the most compelling questions in 21 st century science" (www.deepscience.org), also indicates that the DUSEL project, as all major underground excavation projects, offers fantastic opportunities to cast light on strategic rock mechanics and rock engineering questions. Of the many challenges we face, this paper addresses the need to improve our ability to better understand rock mass behaviour. It would be a mistake if we would not take these opportunities to advance our knowledge and rock engineering state-of-the-art.

Of the many technical challenges in geo-engineering, to build on and in rock, this paper focuses on these aspects:

- Going underground - mining in weak ground.

- Going deeper - mining in stressed ground.

- Going faster - safe, rapid development.

Innovative solutions to overcome related challenges offer opportunities for huge economic gains. For example, to go underground, one major mining company alone has to sink four to five shafts per year and advance on average between 50 and $80 \mathrm{~km}$ of tunnels per year. Progress in the previously listed topics would be highly beneficial.

The value of these opportunities lies primarily in the speed of construction, reduced risks during construction, and enhanced long-term quality of the related infrastructure, i.e. less or little rehabilitation as mining affects the infrastructure. In civil engineering tunnelling, many projects suffer from costly delays; often as a result of engineering that does not facilitate optimal construction (Kaiser, 2006). It can be easily demonstrated that an increase in development rate can reduce the cost of large construction or mining projects by hundreds of millions of dollars. This economic opportunity and the related technical challenges are the driver for innovation and must guide our path of discovery in rock mechanics.

In the following, some lessons learned in recent years are reviewed from a geomechanics perspective to facilitate future problem solving and to identify opportunities for improved rock excavation techniques, support design and other ground control measures. By interpreting observed rock failure processes, by explaining factors affecting constructability, and by questioning some well established principles (e.g. commonly used failure criteria), some deficiencies in our current state of knowledge and thus opportunities for improvements are identified

\section{Anticipating the "true" rock behaviour - a primary geomechanics challenge}

The first principle in understanding rock behaviour is to carefully observe and then interpret field evidence. In this manner, it was found that spalling (or brittle failure) often dominates over shear failure and that this process is highly dependent on rock confinement (both from a strength as well as a rock dilation (bulking) perspective). It should therefore be anticipated that the strength and bulking behaviour near excavation surfaces (open pit or underground) should differ from those encountered at some distance from an excavation. It also follows that fractured rock loses its self-supporting capability (reduced stand-up time) and thus must be more difficult to control during construction (Kaiser, 2006; 2007).

If brittle rock failure behaviour is not anticipated, e.g. when going deeper or when entering highly stressed ground, rock may behave in an unexpected manner, good "old" ground may become bad ground, and proven technologies may fail to perform well. The geotechnical engineer is thus challenged to anticipate changing rock behaviour modes and to design control measures in such a manner as to facilitate ease of construction.

In tender documents, descriptions of the geology and the rock characteristics are often overemphasised while descriptions of the anticipated rock and rock mass behaviour are underemphasised, or, in many cases, the "true" rock mass behaviour is not anticipated. When the actual rock behaviour is not correctly anticipated or even worse misunderstood, inappropriate constitutive models may be used for numerical simulations and resulting stability assessments and support designs may be deficient or impractical causing construction difficulties. 
For this reason, three main elements of underground construction are discussed in more detail: (1) the relevance and consequences of brittle failure processes in underground engineering and construction; (2) challenges in anticipating the rock or rock mass strength when brittle failure processes affect or dominate the failure modes of underground excavations, and (3) the consequences for stability assessment and underground constructions.

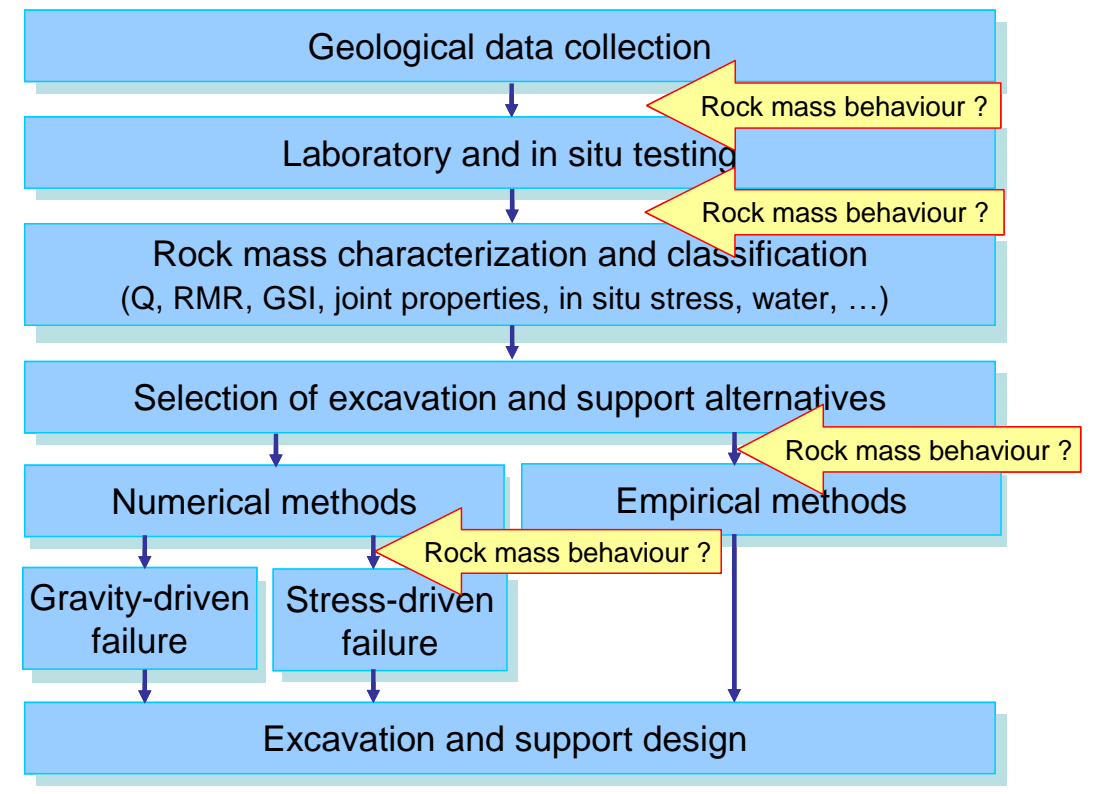

Figure 1 Site characterisation approach for standard geo-engineering projects; the arrows are where a sound understanding of rock mass behaviour is needed

\subsection{Rock behaviour characterisation}

Site or rock characterisation generally follows a well established path (Figure 1) from geological model to rock mass model development, whereby the spatial distributions of rock types (lithologies) as well as rock and rock mass properties (including in situ stress) and characteristics (including jointing, water, etc.) are characterised and classified. However, when stepping out of the world of experience, e.g. by going from shallow to deep tunnelling, costly mistakes can be made because the rock behaviour may change and the rock may behave in an unexpected manner. Furthermore, rock may behave differently when unconfined (near an excavation) or when confined (in the core of a pillar). Hence, it is not sufficient to just provide a geological and a rock mass model; it is necessary to translate the knowledge gained from geological to rock mass and then to rock behaviour models. Most tender documents elaborate much on the geological and rock mass model but fall short of providing proper descriptions of the rock mass behaviour models. In Figure 1, the arrows indicate that the anticipated rock behaviour model should influence many steps in the site characterisation process.

In slope engineering, it is common practice to classify slope behaviour modes (Figure 2); planar, circular, wedge, multi-block failure, etc.) and to match each class with a respective limit equilibrium model (Bishop, Janbu, Hoek and Bray, Morgenstern and Price, Sharma, etc.). Unfortunately, by the proliferation of numerical modelling, with continuum and somewhat less with discontinuum models, this distinction by failure or behaviour mode is often ignored or even misrepresented by the chosen numerical model.

In underground construction, commonly recognised behaviour modes include wedge failure, squeezing, swelling, etc., and these are reflected in respective modelling tools (UDEC, 3DEC, Unwedge, FLAC, Phases, etc.). Almost exclusively, the most commonly recognised behaviour modes are related to shear failure; either along block boundaries or through the rock mass (elements 11-13 and 33 in the tunnel behaviour matrix presented in Figure 3). The effects of tensile failure or spalling are rarely anticipated and correctly modelled, and thus not properly described in tender documents even though it is often the related near excavation degradation process that negatively affects constructability issues such as stand-up time. 
Failure mode

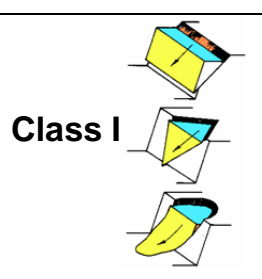

Class II

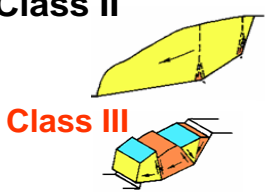

Mechanism

Rigid body motion

Local yielding to allow basal movement

Internal shears and block dilation to allow basal shear
Influence of internal shear

None

Hoek and Bray (1974)

Minor

Morgenstern and Price

(1965)

Major

\section{Method of Analysis}

\section{Figure 2 Slope failure mode classification (after Corkum and Martin, 2004)}

Brittle, tensile rather than shear, failure modes play a role at intermediate to high stress levels and in massive to moderately jointed rock masses (elements 21-23 and 31-32 in tunnel behaviour matrix of Figure 3). In general, brittle rock behaviour near excavations is more wide spread than commonly anticipated. For example, over-consolidated clays like the Opalinus Clay at Mount Terri (Yong et al., 2008, show clear signs of brittle failure (Figure 4). Many weaker rock types such as lightly cemented sandstones, Kimberlites, shales, etc., do also fail in a brittle manner when lightly confined.

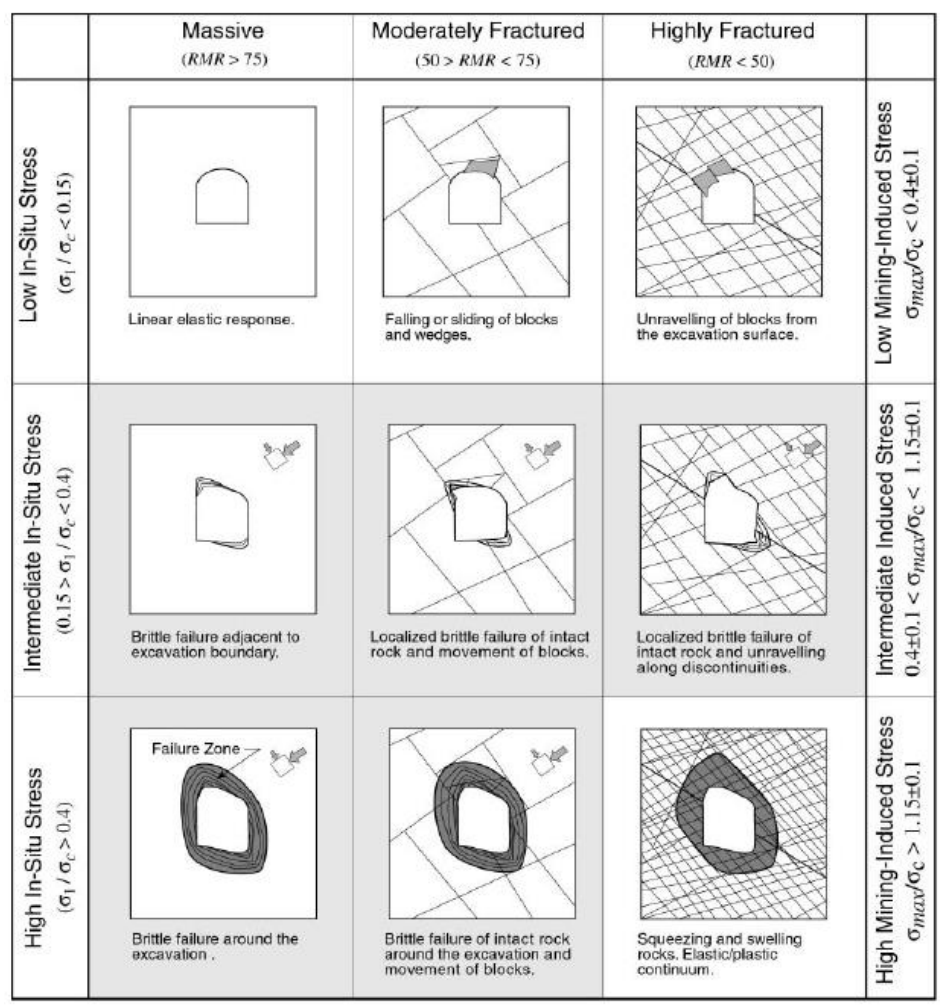

Figure 3 Tunnel failure modes (Kaiser et al., 2000) 


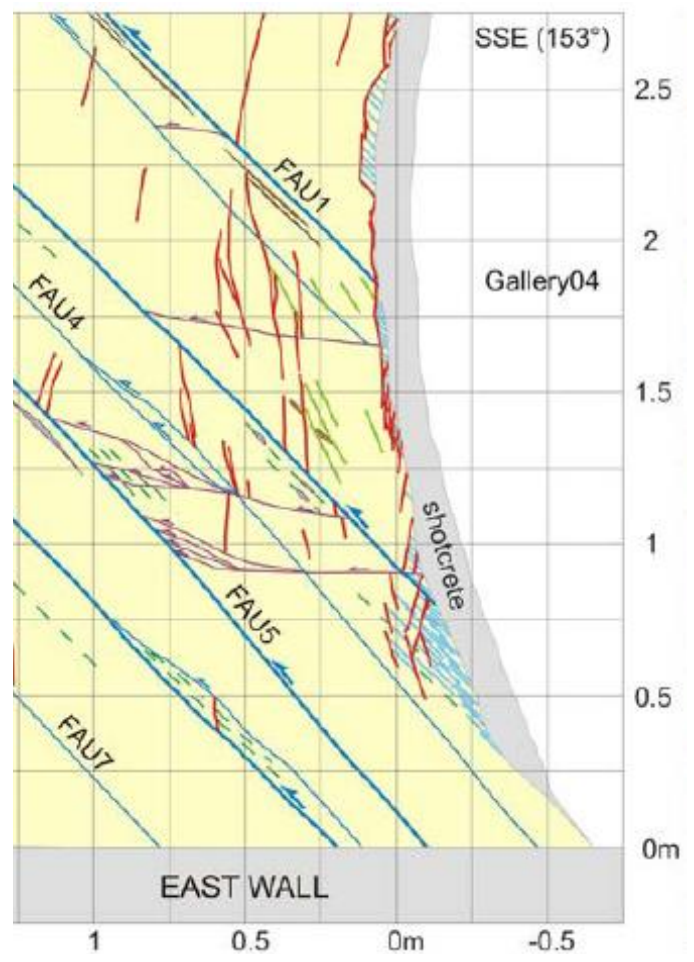

Figure 4 Brittle fracturing near tunnel in Opalinus Clay (Yong et al., 2008)

\subsection{Brittle failure characteristics}

Difficulties in designing underground excavations are often experienced because constitutive laws in numerical models do not necessarily reflect the actual behaviour of the rock. This is particularly true when the fundamental paradigm of the Mohr-Coulomb yield criteria $\tau=c+\sigma_{n} \tan \phi$, relating the shear strength $\tau$ to a strain-independent cohesion $c$ and a simultaneously acting frictional resistance $\left(\sigma_{n} \tan \phi\right)$, is not valid (Martin, 1997; Martin et al., 1999; Kaiser et al., 2000). As intact rock is strained, cohesive bonds fail and damage initiation and propagation occurs at different stress thresholds (Diederichs, 2003). The propagation of tensile fractures depends on the level of confinement (as established by tests of Hoek (1968)) and is used to explain brittle failure by collaborating researchers in Kaiser et al. (2000). Figure 5(a) illustrates that an sshaped criteria is required to properly describe the entire failure envelope from low confinement, spalling failure to high confinement shear failure. The existence of this s-shaped failure envelope for many rock types is further examined and verified in this paper.

A bi-linear or non-linear criterion is required to capture this dependence on confinement in the low confinement range (near excavations) for rock that is prone to spalling (Figure 5(b)). Brittle failure by tensile spalling occurs when the stress path moves above the damage threshold and to the left of the spalling limit. The practical relevance of an s-shaped envelope, reaching into the high confinement range, is discussed by use of a tri-linear failure envelope approximation (Figure 5(c)) with a tension cut-off, a damage limit through $\mathrm{USC}_{\mathrm{I}}$ (lab test), a spalling limit with a slope $\mathrm{k}_{\mathrm{s}}$, and a shear limit with an intercept or apparent unconfined strength UCS II. 


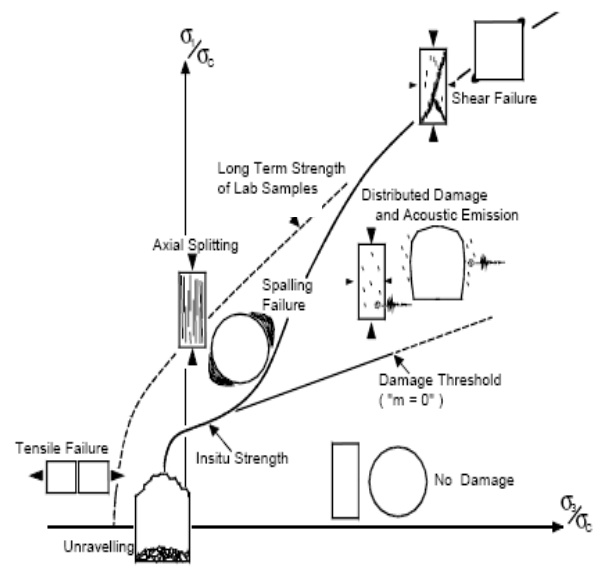

(a)

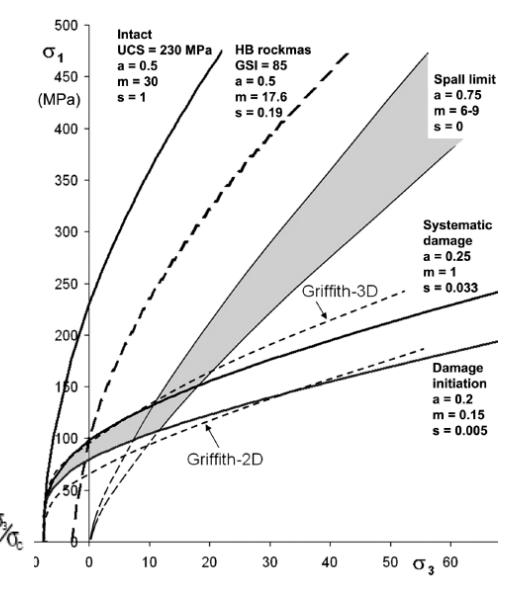

(b)

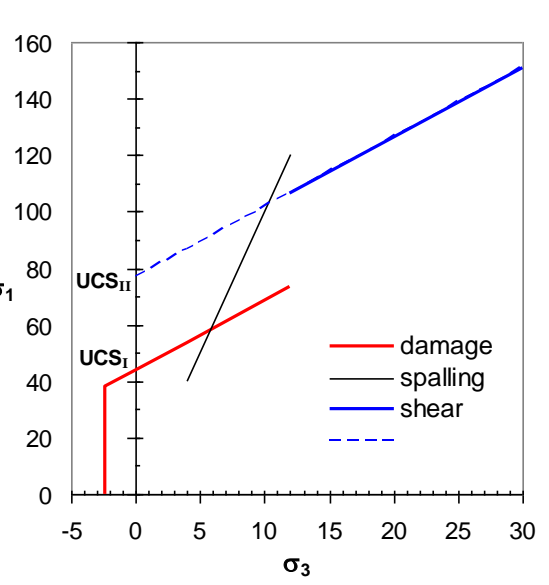

(c)

Figure 5 S-shaped failure criteria concept showing damage threshold, spalling limit and confined rock strength envelope (Kaiser et al., 2000; Diederichs, 2003); (b) bi-nonlinear approximation introduced by Diederichs et al. (2007) for damage threshold and spalling limit; (c) tri-linear failure envelope used for examples presented in Section 2.3

\subsection{Consequences of brittle failure on tunnel behaviour}

\subsubsection{Strength development near excavations}

Contrary to the tangential or major principal stress near an underground excavation, the radial or confinement stress zone is nearly parallel to the excavation geometry as illustrated by Figure 6 . As a consequence, contours of equal rock strength are essentially parallel to the $\sigma_{3}$-contours and the rock strength distribution in the radial direction, with the exception of the floor, is very similar for all three cases and for the walls as well as for the roof. For the tri-linear envelope of Figure 5(c), the spalling limit is reached at about $5 \mathrm{MPa}$ (in the middle of the contour range shown in Figure 6) and the shear failure envelope is reached at about $10 \mathrm{MPa}$ (at the outer range of the contours shown). The development of $\sigma_{3}$ in the wall for the three cases is shown in Figure 7(a) and the resulting strength development in the radial direction is illustrated by Figure 7 (b) for the wall. Since the $\sigma_{3}$-contours are essentially parallel to the tunnel boundary, nearly identical strength developments are applicable for the walls and roof.

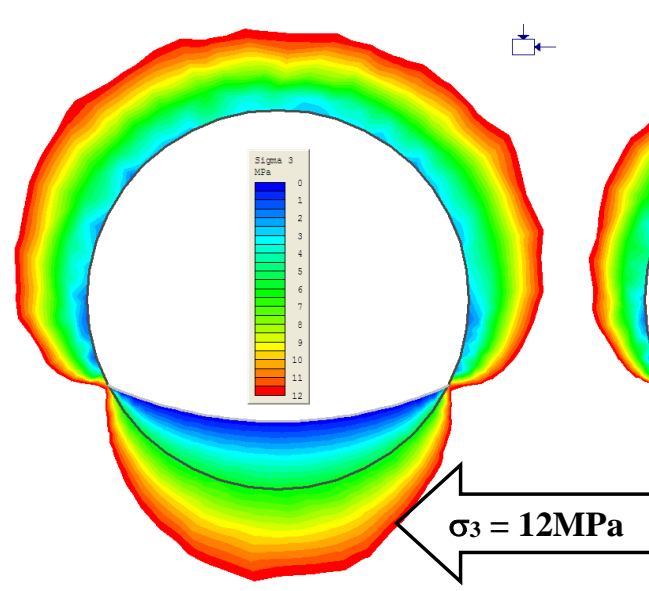

(a)

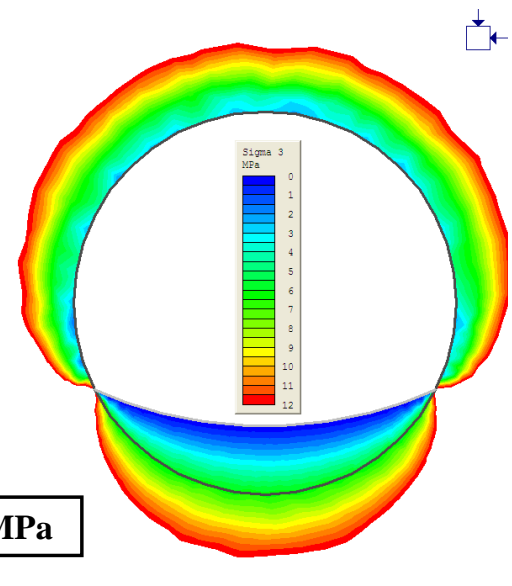

(b)

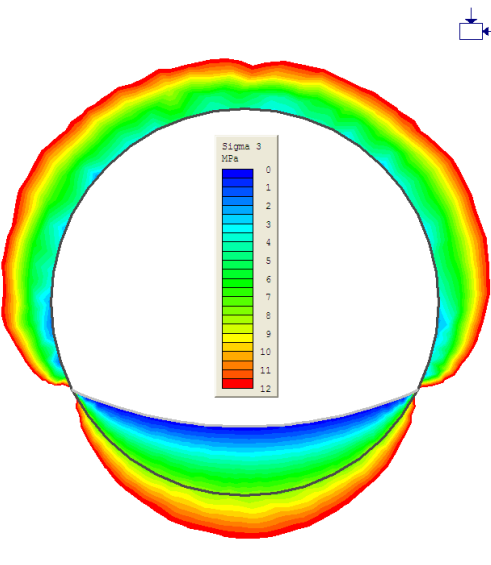

(c)

Figure 6 Minor principal stress contours (range 0-12 MPa) around excavation in elastic rock for $K_{0}=0.75,1,1.33$

Due to the tri-linear or s-shape of the failure envelope, the rock strength, for all three stress ratios, is relatively low near the excavation (to a depth of about $0.7 \mathrm{~m}$ for this case), then rapidly increases to about 
double strength at a depth of about $1.3 \mathrm{~m}$, and then increases further but at a lower rate. The tangential stress $\left(\sigma_{1}\right)$ for $K_{o}=1.33$ is also shown in Figure $7(b)$ for the roof and walls. Due to the flat, reduced strength near the wall, the tangential stress exceeds the strength not just in the roof (where it would be anticipated for $\mathrm{K}_{\mathrm{o}}=1.33$ ) but also in the walls. Field evidence supports this as shallow stress-induced overbreaks were more widely distributed in the roof than would be anticipated from conventional breakout models (Figure 7(c); Kaiser, 2007).

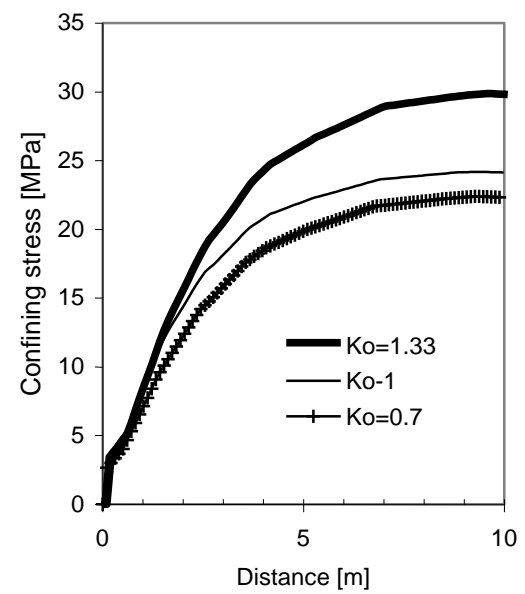

(a)

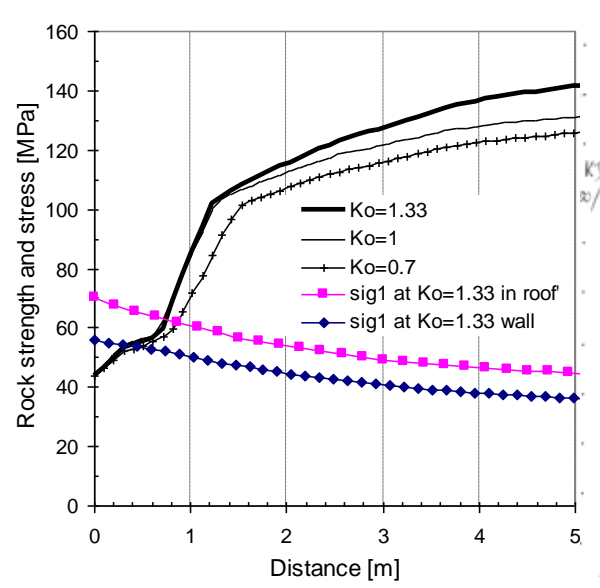

(b)

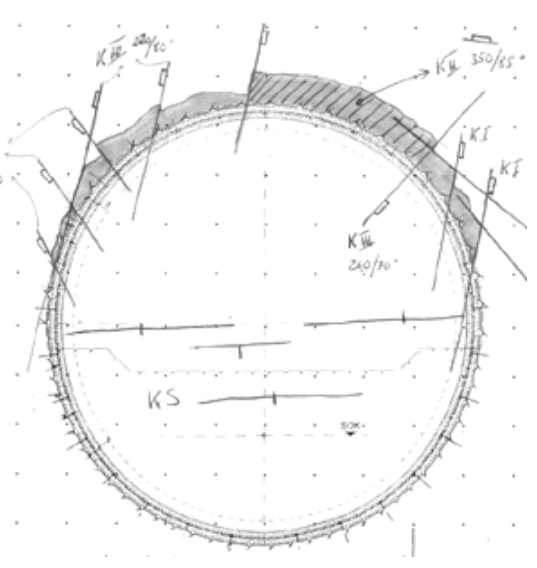

(c)

Figure 7 (a) Radial stress distribution for $K_{0}=0.75,1,1.33$; (b) rock strength development near excavation for tri-linear criteria (Figure 5); (c) observed shallow stress-induced overbreak in $9 \mathrm{~m}$ tunnel excavated in moderately jointed rock

For support design and support selection, to manage brittle rock failure, it is therefore necessary to properly reflect the rock strength near the excavation and this can be properly approximated by a bi-linear or binonlinear envelope (Diederichs, 2003; Diederichs et al., 2007). For pillar stability assessment, however, it is necessary to consider all three parts of the s-shaped curve.

In the floor, the strength increases less rapidly, due to the deeper low confinement zone (Figure 6), thus promoting deeper tensile fracturing and spalling than in the walls and roof. This has several practical consequences.

\subsubsection{Swelling potential enhancement by brittle failure}

Once the damage and spalling thresholds are exceeded, the volumetric deformation characteristic of brittle failing rock changes drastically as tensile fractures tend to open fractures, and geometric incompatibilities between rock fragments lead to high radial dilation (bulking) (Kaiser, 2006). As a consequence, water access to the rock is facilitated through stress fractures, particularly in the low confinement zone of the floor (Figure 6). This increases the supply of water to rock fragments, and when combined with the reduced confinement, enhances the swell potential.

The author hypothesises that brittle failure processes during tunnel advance may play a significant role in rocks where rock degradation processes are facilitated by water ingress, i.e. in rocks with swelling or slaking potential. For example, brittle fracturing may enhance the swelling potential and swelling rates in preconditioned or stress damaged zones, e.g. below flat floors (Einstein, 1996) or below insufficiently curved inverts, because tensile fracturing provides preferential access paths for water in a zone of low confinement. This is illustrated in Figure 8(a) and (b) for a horseshoe-shaped tunnel; the Belchentunnel and a model with $\mathrm{K}_{\mathrm{o}}=1.2$.

While the numerical example presented here does not take into account the confining effect of a liner, these figures clearly illustrate that brittle rock tends to preferably spall and fracture in the floor, even when a curved invert is used. As the radius of the invert is reduced and thus deepened, the amount of fractured rock is reduced and it is speculated that this is, at least in part, responsible for lower swelling pressures in tunnels with circular profile or with deep floor arches. 

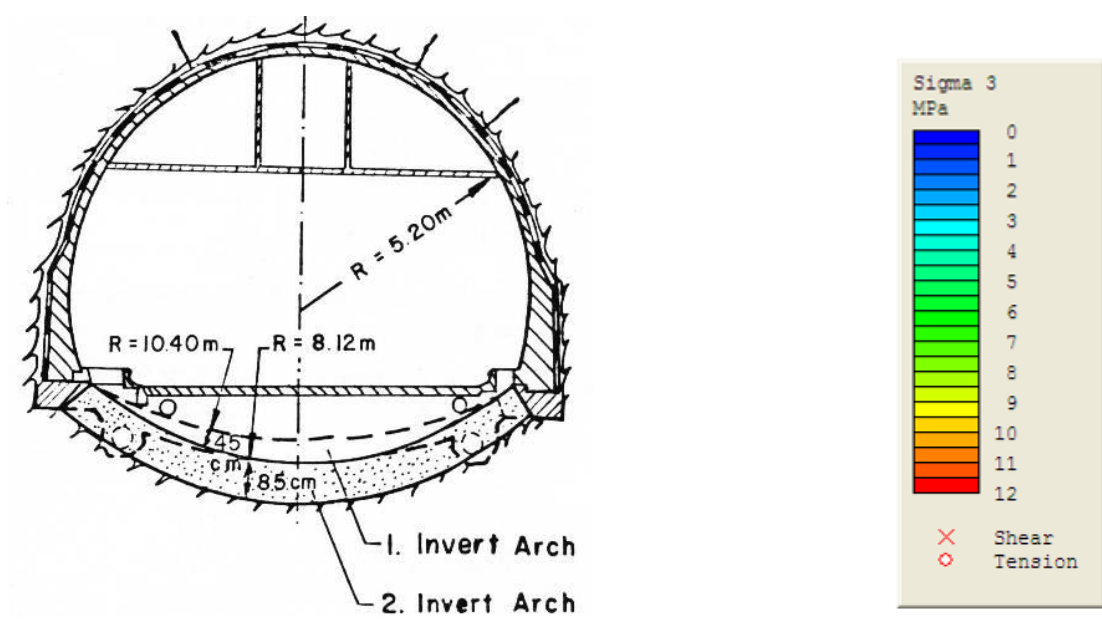

(a)

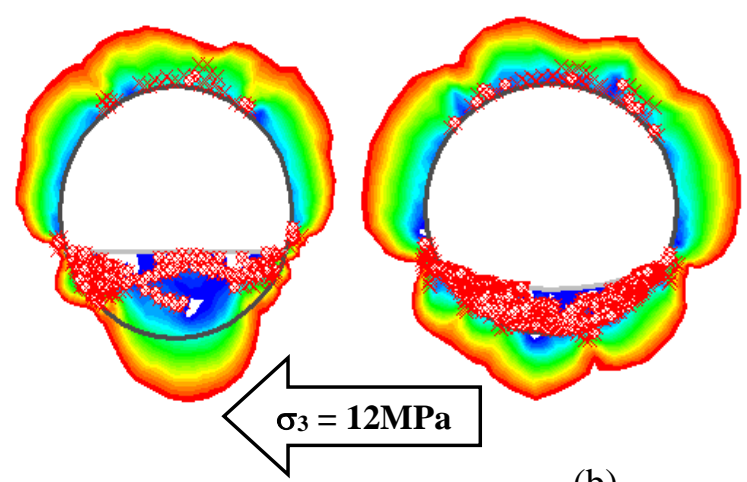

(b)
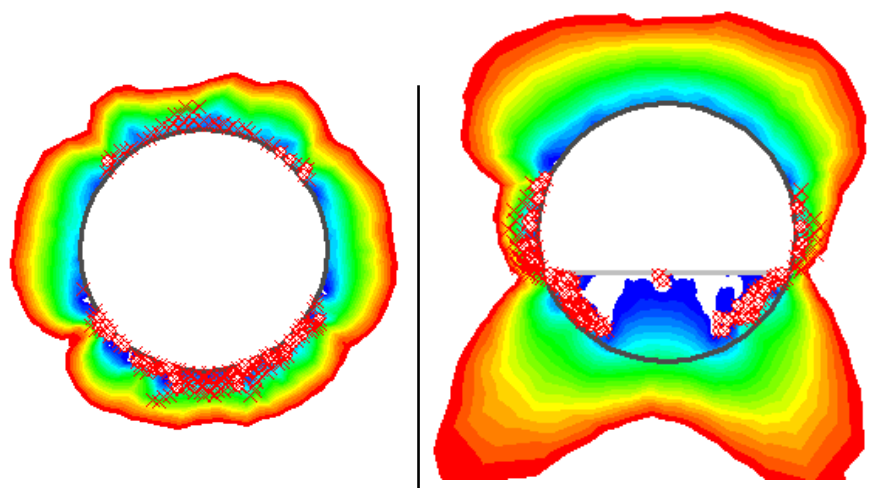

(c)

Figure 8 (a) Belchentunnel (Grob, 1972) showing pre- and post-reconstruction invert arches; (b) $K_{0}=1.2$ : flat, curved and circular invert; shown are tensile and shear failure (o and $x$ ) and $\sigma_{3}$-contours (0-12 MPa); (c) minor principal stress contours for $K_{0}=0.5$ with tensile and shear failure locations

\subsubsection{Enhanced slaking potential due to brittle failure}

In rocks that are prone to slaking (softening and weakening due to water ingress), brittle failure processes can lead to preferential water access paths and thus to non-uniform slaking. In Kimberlites, for example, it is often observed that tunnels are initially stable and may even show signs of fracturing (spalling), but that, after some time, squeezing behaviour starts to dominate the tunnel behaviour. Tensile fracturing again can provide preferred access paths for water and thus regionally enhanced slaking potential.

While the extent and location of spalling will differ in various rock types (properties), Figure 8(c) illustrates for $\mathrm{K}_{\mathrm{o}}=0.5$ that both the lower walls and floor are most susceptible to tensile fracturing and thus, as a consequence, to slaking. This is in good agreement with frequently observed degradation processes.

Recent advances in modelling techniques involving fracture propagation (e.g. ELFEN, Rockfields, UK) and models permitting combined failure modes involving discontinuities and intact rock (e.g. synthetic rock mass (SRM) model) will eventually facilitate the proper simulation of combined shear and tensile failure processes. For the time being however, much can be achieved by recognising the impact of the s-shaped failure envelope on excavation behaviour and by approximating it by a bi-nonlinear envelope for support design and by a tri-linear envelope for aspects involving unconfined and confined rock (pillars, cave propagation, etc.). 


\subsubsection{Strength development in brittle failing pillars}

As indicated previously, for pillar stability assessment, it is necessary to consider all three parts of the sshaped curve (Figure 5(a) and (c)) if the confinement inside the pillar exceeds the $\sigma_{3}$-value at the intersection of the spalling limit and the shear failure envelope (about $\sigma_{3}=10 \mathrm{MPa}$ for case shown in Figure 5(c)). Martin and Maybee (2000) used brittle Hoek and Brown parameters (Martin et al., 1999) to demonstrate that the pillar strength, contrary to the best-fit curves presented by many (Figure 9(a)), should non-linearly increase (with an upward rather than a downward curvature) as the pillar width to height ratio $(\mathrm{W} / \mathrm{H})$ increases. The authors justified this by the fact that spalling or hour-glassing weakens narrow pillars more than wide pillars. Their interpretation also makes intuitive sense as very wide pillars should approach the strength of the confined rock mass, which should be much higher than suggested by the horizontal asymptotic value of about 0.7 UCS, as indicated in Figure 9(a). The development of stresses and strength for two pillar sizes, $\mathrm{W} / \mathrm{H}=1$ and 2, are shown in Figure 9(b). Near the wall, the damage threshold is reached and the local factor of safety FS = strength/stress $=1$ and the major principal stress (sig1) is reduced as a consequence. The confining stress (sig3) reaches about $18 \mathrm{MPa}$ in the centre of both pillars and the shear failure envelope (Figure 5(c)) defines the strength of the pillar core. For the rock properties given in Figure 5(c), the strength in the core far exceeds the pillar stress and the local factors of safety (FS) reach 3 and 4.5 for the two pillars, respectively. The overall factors of safety (average pillar strength/average pillar stress) are 3.5 and 2.2, respectively, indicating that both pillars would spall (hour-glass) but would be overall stable due to a stable core. It follows that the pillar strength is strongly influenced by the confined strength of the rock mass and thus by the third leg (the shear strength) of the s-shaped envelope.

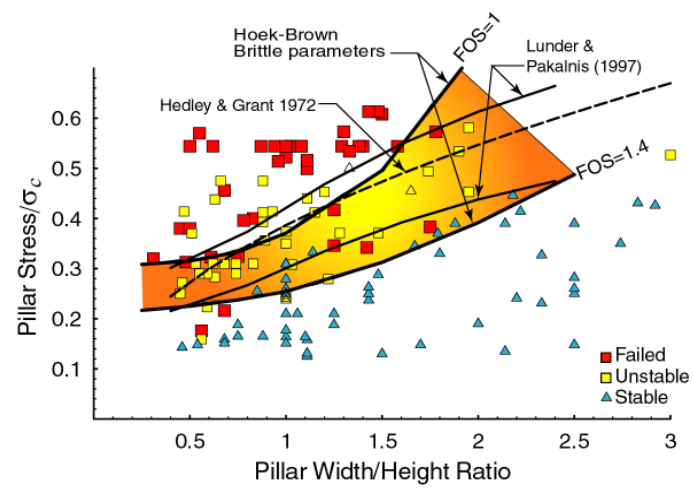

(a)

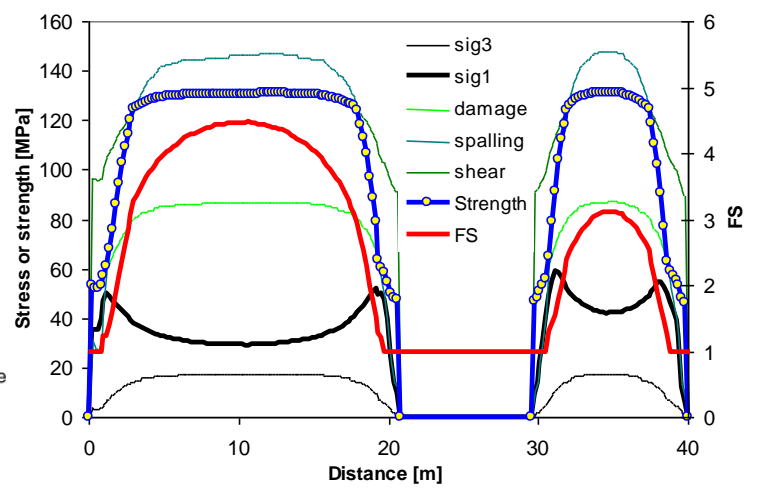

(b)

Figure 9 (a) Pillar strength (Martin and Maybee, 2000); (b) distributions of pillar stress, strength and factor of safety (FS) for two pillars $(\mathrm{H}=10 \mathrm{~m} ; \mathrm{W} / \mathrm{H}=2$ and 1$)$ at $1100 \mathrm{~m}$ depth with $\mathrm{K}_{0}=\mathbf{0 . 6}$

\subsubsection{Potential impacts on cave propagation}

While cave propagation is a complex phenomenon and beyond the scope of this paper, it is worthwhile noting that the strength distribution shown in Figure 7(b) has two potential practical implications: (1) the reduced strength in the shallow, low confinement zone (inner shell) may promote break-up of the rock mass into relatively small size blocks (production of smaller than typically anticipated fragmentation); and (2) the rapid increase of strength in the deeper, high confinement zone (outer shell) may tend to choke the cave propagation process. These aspects deserve further study and thus present an opportunity for technical advancement.

\subsubsection{Rock support considerations for brittle failing rock}

As illustrated by Figure 6, a low confinement zone of more or less constant depth exists near an unsupported excavation. Even if the tunnel was supported with a liner providing a radial support pressure (typically between 0 and $1 \mathrm{MPa}$ ), such a low confinement zone still exists. Hence, the damage threshold defines the rock strength near the excavation as shown in Figure 7(b). However, the strength rapidly increases as soon as the confinement is sufficient to reach the spalling limit (at about $0.7 \mathrm{~m}$ depth or $\sim 5 \mathrm{MPa}$ in Figure 7(b)). 


\subsubsection{Rock mass bulking control}

As illustrated by Figure 10(a) for a deep tunnel, tensile fracturing (circles) is largely confined to the inner hell of about $1.5 \mathrm{~m}$ depth in this case. Most importantly, this figure illustrates that tensile failure induced spalling should be expected all around the tunnel, even for $\mathrm{K}_{\mathrm{o}}=0.5$. This is consistent with the observed overbreak profile shown in Figure 7(c). Since damage by tensile fracturing is affected by the tensile strength of the rock (tension cut-off), the actual location of stress fracturing can vary in anisotropic rock as the tensile strength perpendicular to foliation is often smaller than parallel to it. Hence, in a horizontally foliated rock (e.g. gneiss), the back would be more prone to stress fracturing than the walls. This was the case at the tunnel illustrated by Figure 7(c).
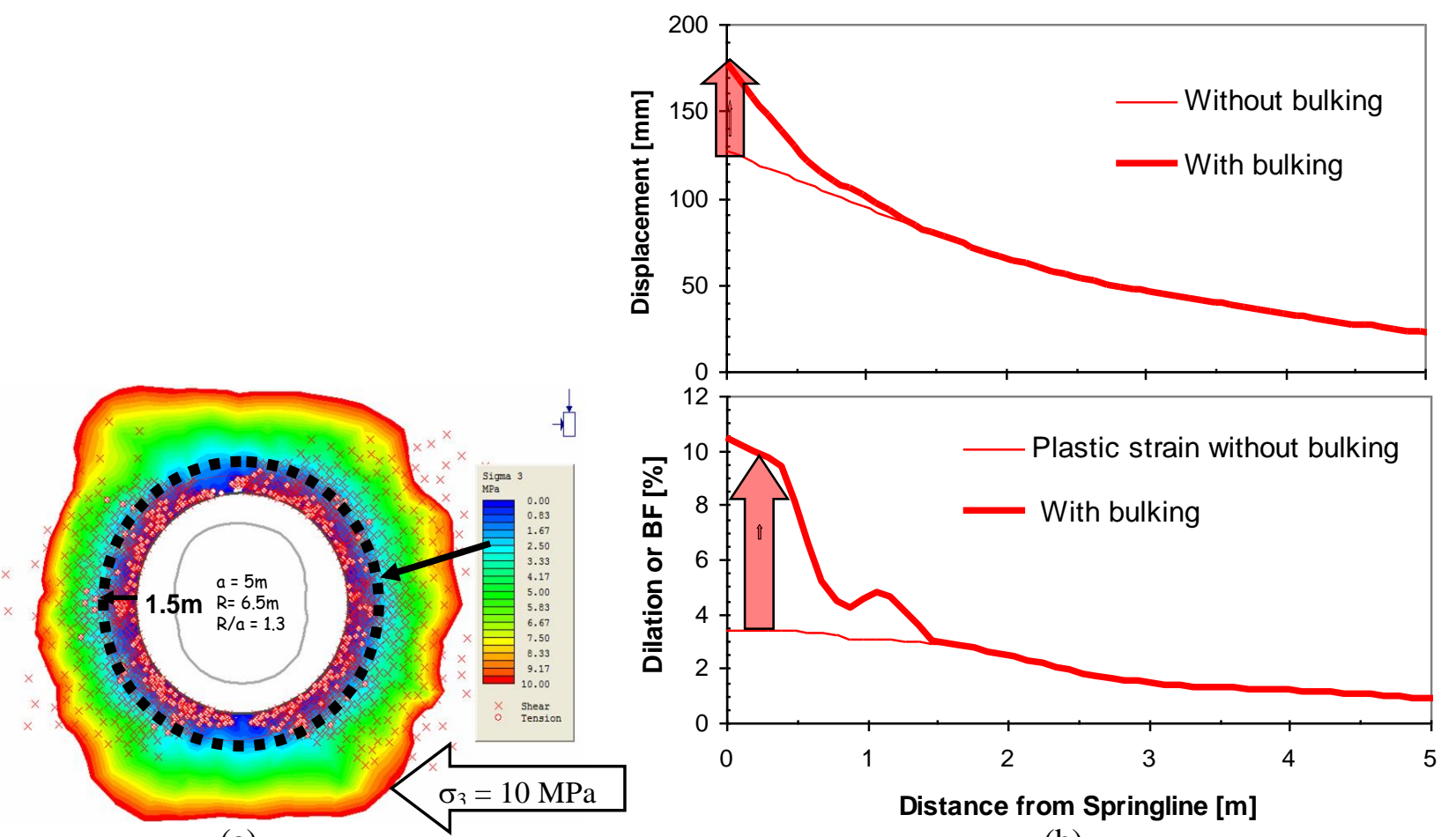

(a)

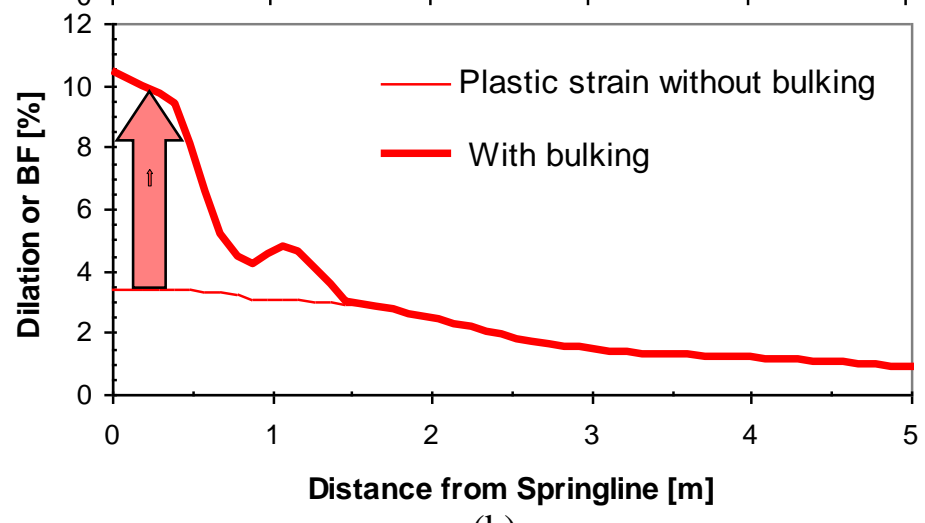

(b)

Figure 10 Tunnel at $2000 \mathrm{~m}$ depth with $\mathrm{K}_{0}=\mathbf{0 . 5}$; (a) $\sigma_{3}$-contours showing an almost circular (inner) zone of low confinement; (b) corresponding radial dilation or bulking factor (\%) and resulting cumulative displacement with $41 \%$ more convergence due to bulking

Kaiser (2007) illustrated bulking in the stress fractured zone. It was shown by numerical modelling that bulking is highly dependent on confinement. For typical support pressures of $\leq 1 \mathrm{MPa}$, bulking increases rapidly to values in the range of $7-10 \%$. This is consistent with bulking factors derived from field measurements (Kaiser et al., 1996) showing > 30\% for unconfined floors and 1-10\% depending on support type. As a consequence, the radial strains in the inner shell are much larger than predicted by standard constitutive models. For a given parameter set with an elasto-plastic rock mass behaviour model, Figure 10(b) shows how the radial strain increases toward the tunnel (maximum about $3.5 \%$ at the tunnel wall for the selected parameter set). Due to the superimposed bulking process, the total or combined strain is much larger to a depth of about $1.5 \mathrm{~m}$, reaching $>10 \%$ at the wall (Figure 10(b)). The cumulative displacements without and with bulking is shown in the upper diagram of Figure 10(b). The consequence of bulking in the first $1.3 \mathrm{~m}$ is a $41 \%$ increase in tunnel convergence.

It follows for support design that, contrary to the pillar strength, the wall strength is strongly influenced by the low-confinement strength of the rock mass, i.e. by the first and second leg of the tri-linear failure envelope (the damage and spalling strength). For brittle failing rock, support needs to be designed/selected to control (reduce) the bulking and manage the resulting elevated convergences. 


\subsubsection{Stand-up time management}

Stress-driven rock "fragmentation" in the inner, low confinement shell creates broken rock with varying fragment size and shape distributions (Kaiser, 2007). This degradation is plotted on the GSI chart (Cai et al., 2006; Figure 11), showing that stress-driven degradation transforms a rock mass of GSI $>65$ to a damaged, fractured rock mass of $35<\mathrm{GSI}<55$ and, most importantly, from a continuum or tight discontinuum, often with non-persistent joints, to a loose discontinuum with often continuous and open fractures.

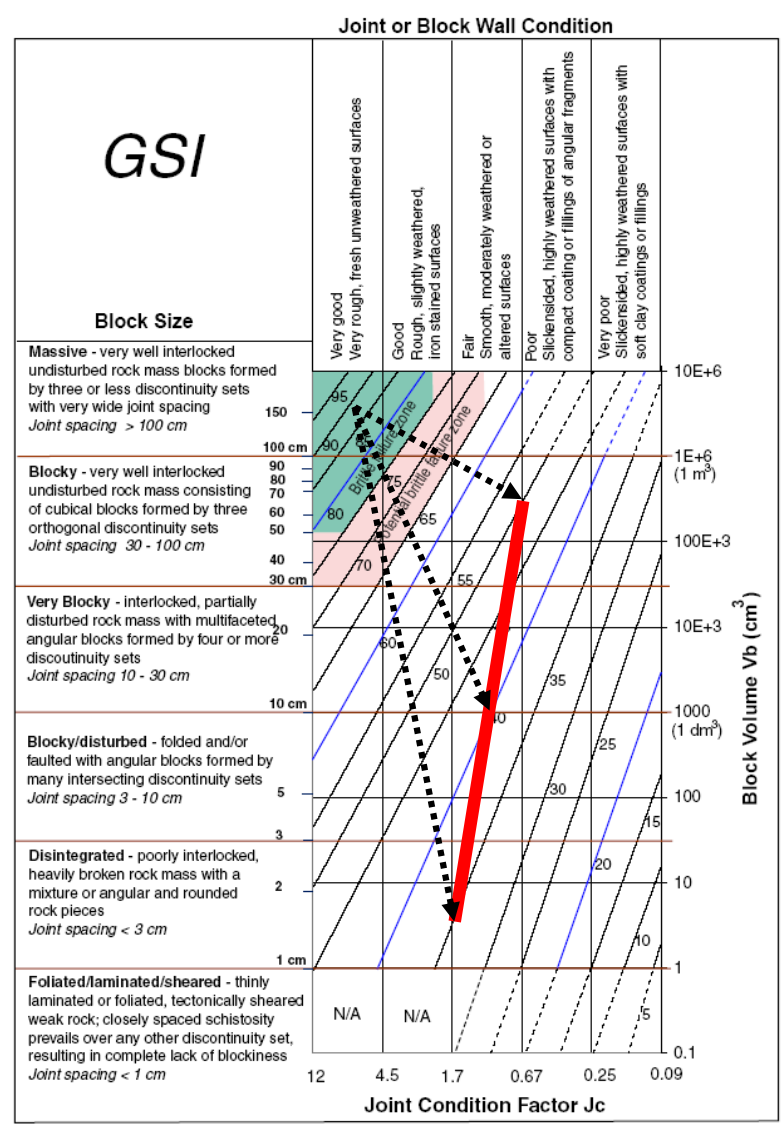

Figure 11 GSI-chart showing degradation paths for various rock types from massive gneiss, to friable quartzite, to massive granite (Kaiser, 2007)

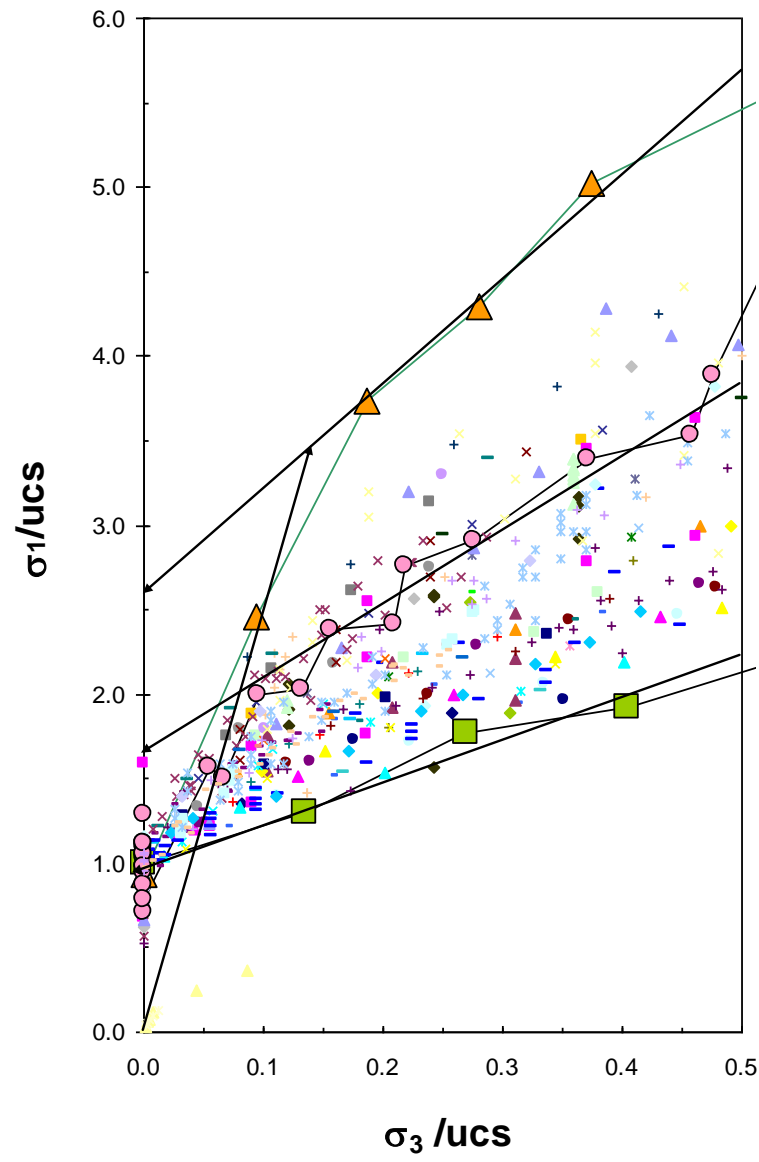

Figure 12 Triaxial test data from tests on 73 rock types (data courtesy E. Hoek (pers. comm., 2008))

When rock is excavated, the stress path eventually ends in a nearly unconfined state (in the spalling zone of Figure 5(a) for brittle rocks). According to the stand-up-time chart (Bieniawski, 1989) essentially permanent stability, with stand-up times of several months to greater one year, can be achieved (for a 5-10 m wide unsupported tunnel) when RMR $\geq 65 \pm 5$ or GSI $\geq 60 \pm 5$. However, only very short stand-up times, say 6-24 hours, can be achieved when RMR $\leq 40 \pm 5$ or GSI $\leq 35 \pm 5$. From a constructability perspective this implies that it is difficult to retain stability in the inner shell when stress-driven fracturing causes rock degradation in the inner shell. However, while it may be difficult to retain the broken rock, the demand on the support will be often rather limited due to stronger rock in the outer shell.

Stress-driven fracturing and rock mass degradation can bring a stable, self-supporting rock mass to the brink of ravelling with low to zero stand-up times. In other words, brittle failure processes will tend to cause constructability problems as the fractured rock mass near the excavation will not be self-stabilising. Such rock behaviour has slowed the rate of progress at various projects utilising open tunnel boring machines (Kaiser, 2007). 


\subsection{Laboratory test data revisited}

Based on the previously presented consequences of brittle rock failure, it is clearly necessary to re-evaluate and reconsider constitutive models used in rock mechanics.

Both Mohr-Coulomb and Hoek and Brown assume a steady increase in strength with increasing confinement; a linear increase for the former and a non-linear increase for the later. More importantly, for both criteria it is implied that cohesive and frictional strength components are simultaneously mobilised. Furthermore, rock mass degradation, e.g. using GSI, does not change the form of the failure envelope, and various means for residual strength determination (Cai et al., 2006) do also not alter the shape of the peak strength envelope.

Ample evidence has been presented in the recent literature by colleagues (Diederichs and Martin; see list of references) and other researchers that support the bi-linear or bi-nonlinear shape of the failure envelope of rock (Figure 5(a) and (b)). This is now well established based on field observations and extensive backanalyses of cases involving spalling failure.

However, if this process is a fundamental characteristic of brittle failing rock, it should also be observed in the laboratory. Indeed, when testing hard rocks, it is often observed that samples fail, particularly in unconfined or low confinement tests, by axial splitting, shattering or by progressive spalling. Only at high confinement levels or when a sample contains distinct foliation or weakness planes are typical shear failure processes observed. Hence, it should be anticipated that brittle rocks might show a similarly bi-linear or sconfinement levels or when a sample contains distinct foliation or weakness planes are typical shear failure shaped failure envelope as back-analysed from field observations.

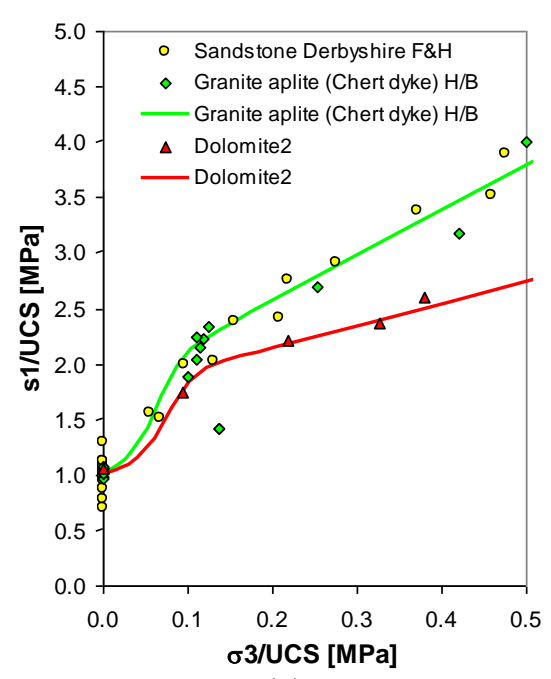

(a)

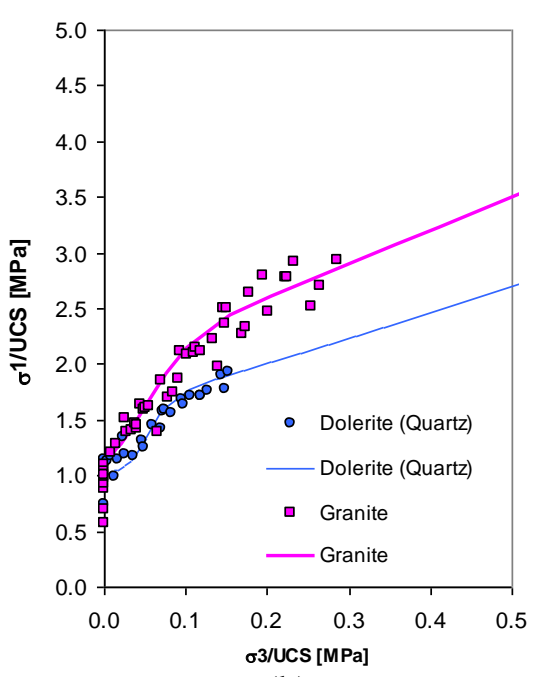

(b)

Figure 13 Laboratory test data fitted with s-shaped failure criteria (data courtesy E. Hoek, pers. comm.)

\subsubsection{S-shaped failure criteria for brittle failing intact rock}

Figure 12 presents data contained in Dr Hoek's database with three of over 70 rock types highlighted (the strongest, the weakest and one intermediate rock type). Also shown is a spalling limit at $\sigma_{1} / \sigma_{3}=25$ (arrow from origin) and three linear back-projections (arrows pointing to ordinate; Figure 12) intersecting for the three rock types at $\sigma_{1} / \mathrm{UCS}_{\mathrm{I}}=2.6,1.65$, and 1.0.

While data maybe missing in the low confinement range for some rock types, this figure suggests that there may indeed be a reduced strength zone for $\sigma_{3} \leq \mathrm{UCS}_{\mathrm{I}} / 10$. This is most evident from the data shown in Figure 13(a) for Sandstone, Granite Aplite and Dolomite. While less pronounced, it is also detectable from the Dolerite and Granite tests shown in Figure 13(b). Fitted s-shaped failure criteria are shown for each rock type. The strength in the shear failure zone can be described with an apparent unconfined strength, UCS II $_{\text {, of }}$ 1-2.6 times the UCS obtained from standard unconfined compression tests $\left(\mathrm{UCS}_{\mathrm{I}}\right)$. 
Figure 14(a) presents data from a series of triaxial tests on a Quartzite. The scatter in the low confinement range $\left(<\mathrm{UCS}_{\mathrm{I}} / 10\right)$ is large and can be attributed to various degrees of sample disturbance and varying failure modes (breakage of intact rock near upper limit; failure along pre-existing weakness planes near lower limit; and mixed modes of failure near the fitted s-shaped line).

An s-shaped failure criterion for brittle rock is under development by the authors and the fitted lines to all data as well as for the upper and lower limit is shown in Figure 14(a). In the interim, the laboratory strength can be approximated by a tri-linear criteria as illustrated in Figure 5(c), used for the presented examples, or as superimposed on Figure $14(\mathrm{~b})$ for the Quartzite $\left(\mathrm{UCS}_{\mathrm{I}}=140 \pm 30 \mathrm{MPa} ; \mathrm{UCS}_{\mathrm{II}}=300 \pm 15 \mathrm{MPa} ; \mathrm{k}_{\mathrm{s}}=35\right.$ to 15 to 10 for intact to structurally controlled breaks).

\subsubsection{Guidelines for design parameter selection for brittle intact rock}

It is evident that design parameters for brittle failing rocks must be selected with extreme care and with the design problem in mind. Until an s-shaped failure criterion has been formalised, tested and is ready for use in numerical modelling, constitutive model and failure envelope adopted for support design may have to differ from those used for pillar design. This is illustrated here for the data set shown in Figure 14(a). The average UCS for this rock (data not shown) is $95 \mathrm{MPa}$. Parameters for four approaches are listed in Table 1 and the corresponding non-linear envelopes are shown in Figure 14(c).

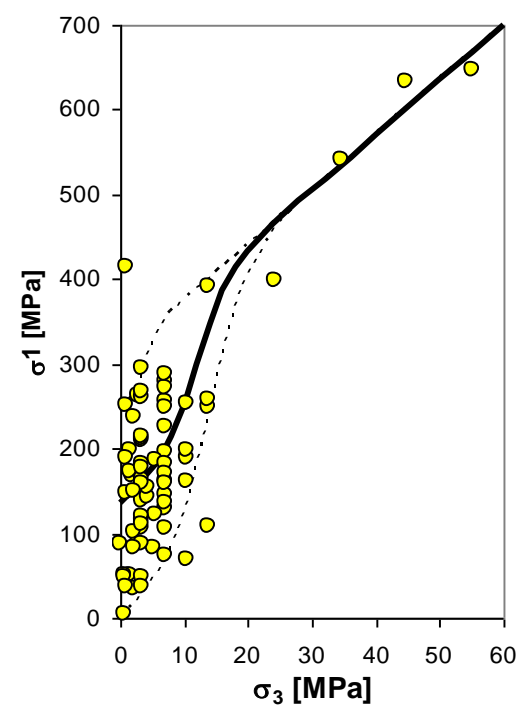

(a)

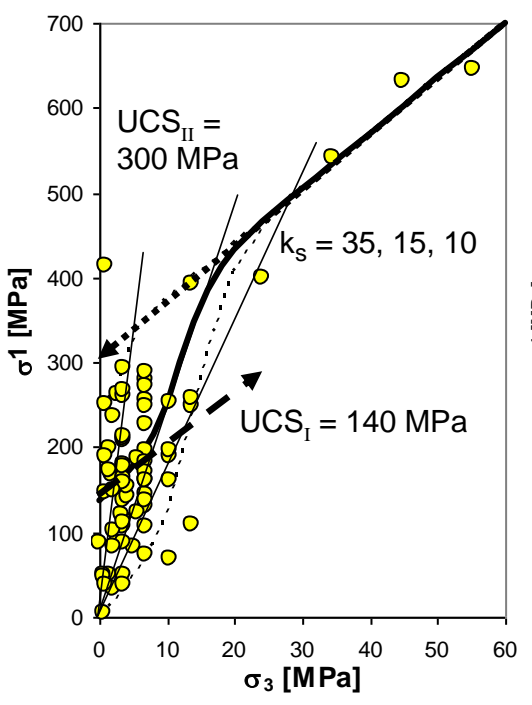

(b)

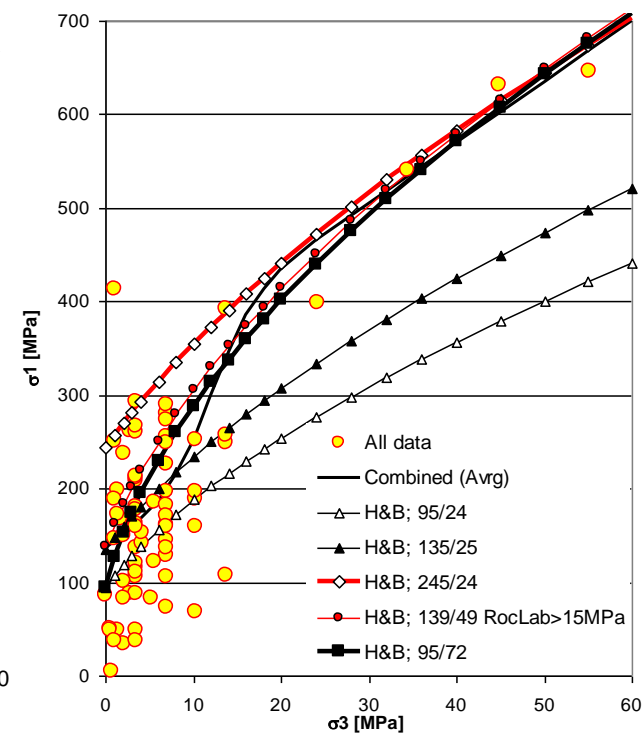

(c)

Figure 14 Data from friable Quartzite (a) fitted s-curve for all data and upper and lower limit; (b) respective linearised approximations; (c) Hoek and Brown envelopes obtained by various fitting approaches with parameters listed in Table 1 (UCS and $\mathrm{m}_{\mathrm{i}}$ values shown in legend as $\mathrm{UCS} / \mathrm{m}_{\mathrm{i}}$ )

Table 1 Parameters for Hoek and Brown criteria shown in Figure 14

\begin{tabular}{llcc}
\hline & Approach & UCS (MPa) & $\mathrm{m}_{\mathrm{i}}$ \\
\hline A & Average from UCS tests and & 95 & 24 \\
& $\mathrm{~m}_{\mathrm{i}}$ from published rock type tables: $\mathrm{m}_{\mathrm{i}}=23 \pm 3$ for Quartzite & $\begin{array}{c}\text { (average) } \\
\text { (assumed) }\end{array}$ & 139 \\
B & RocLab & 50 \\
C & RocLab (Rocscience) applied to all data & 245 & 24 \\
D & Best fit to all data without RocLab constraint of $\mathrm{m}_{\mathrm{i}} \leq 50$ and average UCS & 95 & 72 \\
\hline
\end{tabular}

The obvious question arises: how to select the most appropriate intact rock strength envelope for this Quartzite? The $\mathrm{m}_{\mathrm{i}}$-values for approach $\mathrm{B}$ and $\mathrm{D}$ are clearly out of $\mathrm{m}_{\mathrm{i}}$-range based on commonly 
recommended values for $\mathrm{m}_{\mathrm{i}}$ and thus would be rejected. However, based on the above presented discussion, an unusually high $\mathrm{m}_{\mathrm{i}}$-value of 72 would clearly overall best represent the results from the laboratory testing program (Figure 14(c)).

\subsubsection{Approach A and C: approximation using UCS data from laboratory tests and published $m_{i}$-values}

In mining, modelling is often based on UCS data only and $m_{i}$ is estimated from recommended property tables (Hoek, 2007). The resulting failure envelope (approach A) clearly underestimates the strength of the Quartzite in the high confinement range (> $1 \mathrm{MPa}$; Figure 14(c)) if the average UCS is used. On the other hand, if the UCS of only those tests with intact breaks were used (approach C), then the resulting failure envelope clearly over-estimates the strength of the Quartzite in the low confinement range $(<10 \mathrm{MPa}$; Figure 14(c)).

\subsubsection{Approach B and C: use of RocLab ${ }^{\mathrm{TM}}$}

When using any fitting procedure to obtain Hoek and Brown parameters, data must cover the confinement range of $\sigma_{3}=0$ to $\mathrm{UCS} / 2$. Because of test cell constraints, triaxial tests are commonly conducted with confining pressures up to $60 \mathrm{MPa}$. Consequently, as for the Quartzite, fitting approaches to obtain Hoek and Brown parameters are strictly only applicable for rocks with UCS $<120 \mathrm{MPa}$ thus parameters can, strictly speaking, not be obtained for hard brittle rocks. Furthermore, RocLab ${ }^{\mathrm{TM}}$ limits $\mathrm{m}_{\mathrm{i}}$ to 50 and thus cannot be used for rocks with distinct s-shaped failure behaviour.

\subsubsection{Obtaining representative Hoek and Brown parameters for rocks with s-shaped failure behaviour}

For rocks with distinct s-shaped failure behaviour, a best-fit Hoek and Brown parameter set can be obtained by linear regression in the $\left(\sigma_{1}-\sigma_{3}\right)^{2} / \mathrm{UCS}$ versus $\sigma_{3}$ space (approach D; forcing linear regression line through $\left.\left(\sigma_{1}-\sigma_{3}\right)^{2} / \mathrm{UCS}=1\right)$. However, it must be noted that the corresponding $\mathrm{m}_{\mathrm{i}}$-value $\left(\mathrm{m}_{\mathrm{i}}=72\right.$ for the Quartzite) are unusually high and that standard approaches to obtain the rock mass strength (e.g. by GSI-based degradation) may not be applicable. Nevertheless, such a fitting approach will lead to a parameter set for the intact rock that is on average representative for the entire confinement range (with high uncertainty in the low confinement range).

\subsubsection{Sectional fitting for limited confinement ranges}

For rocks with distinct s-shaped failure behaviour, it is therefore more appropriate to consider the confinement range relevant for a given engineering problem before fitting and selecting design parameters.

For support design, the rock behaviour near the excavation, in a confinement range of $0-5 \mathrm{MPa}$, is most relevant. From Figure 14(c) it follows that the parameter sets, between 95/24 to 139/24, or 120/24 on average with a standard deviation of about $40 \mathrm{MPa}$ on UCS, would be appropriate for the low confinement zone (inner shell). However, a cut-off as recommended by Diederichs et al. (2007), or with $\mathrm{k}_{\mathrm{s}}=15-10$, would have to be applied to prevent excessive depths of failure predictions.

For pillar design, the rock behaviour in the pillar core, in a typical confinement range of $>5 \mathrm{MPa}$ for mining at depth, is most relevant. From Figure 14(c) it is evident that the parameter sets (245/24) with a standard deviation of about $15 \mathrm{MPa}$ on UCS, would be appropriate for the highly confined zone (outer shell). However, the effect of spalling and hour-glassing is to be predicted by using the parameter set for the inner shell.

\subsubsection{S-shaped failure criteria for brittle failing rock masses}

Procedures to obtain corresponding s-shaped failure envelopes for the rock mass, following the GSI approach, are under development by the authors. If it is assumed that the currently adopted degradation approach to obtain the Hoek and Brown parameters $s$ and $m_{b}$ for the rock mass is applicable, then it could be applied for each section of the s-curve (the low and the high confinement range) to obtain an s-shaped rock mass envelope. However, this aspect will require further work and calibration. It remains an outstanding challenge for rock engineering in brittle rock masses. 
Nevertheless, rock and rock mass strength parameters for brittle failing rock should be established separately for low and high confinement zones and then applied to zones where each mode is dominating the rock behaviour (e.g. for inner and outer shell modelling).

\section{Conclusion - lessons learned}

When mining in brittle ground, the rock behaviour can change drastically when progressing to greater depth or when stresses change due to advancing mining fronts.

\subsection{Engineering for brittle behaviour}

By observing and interpreting brittle rock behaviour, it is now possible to understand and anticipate the rock behaviour such that design and construction procedures can be matched to the ground. As a consequence of brittle failure processes, the ground becomes less forgiving at depth as stress breaks even good ground and disintegrates massive to moderately jointed rock to cohesionless ground (at least in the inner shell). As a consequence, this leads to a quantum shift in construction difficulties, e.g. it affects stand-up times, and thus engineering must address this by providing appropriate ground control measures and excavation tools.

At depth, rock becomes brittle and fails at least in part by tensile failure processes. This degradation cannot be prevented but must be managed by appropriate rock reinforcement and retention techniques.

Design based on convention failure criteria (Mohr-Coulomb or Hoek and Brown) may mislead designers. This is of particular concern when numerical codes with conventional constitutive models and inappropriate strength parameters are adopted. As a consequence, failure may both be over- or under-predicted depending on which part of the s-shaped behaviour dominates the rock strength parameter selection.

Due to the distinctly different behaviour in the inner shell, extreme care must be taken when using measurements from the low confinement zone to determine confined rock parameters (e.g. for pillar design). There is a distinct possibility that back-analyses will significantly underestimate the confined rock mass strength and thus lead, for example, to conservative pillar designs.

\subsection{Anticipating construction problems}

With respect to anticipating underground construction difficulties, it is most important to recognise that the rock and rock mass strength near the excavation may be significantly reduced for brittle rock near the excavation (in the inner shell). Hence, spalling, strainbursting, limited stand-up time of the inner shell, and high potential for overbreak should be anticipated. Equipment (e.g. type of TBM) is to be selected to properly manage these unfavourable rock behaviour modes.

Such processes cannot only occur at the excavation (pillar) walls or tunnel backs but in the floor and at the tunnel face. The latter may lead to tunnel face instability issues (Kaiser, 2006; 2007) with related implications for the utilisation of TBMs, and the former may lead to floor heave or degradation (including slaking and swelling) potential.

In summary, spalling processes must be understood when selecting excavation and support techniques; they must be appropriate to manage broken ground.

\section{Acknowledgements}

Some of the studies presented in this paper were partially funded by the Natural Sciences and Engineering Research Council of Canada and contributions of former graduate students and long-term research collaborators listed in the quoted references are thankfully acknowledged. Much practical experience reflected in this paper stems from valuable collaborations with representatives of underground contractors (MATRANS and TAT consortia, Switzerland), TBM manufacturer (Herrenknecht AG, Germany), mining companies (Vale Inco, Goldcorp, Rio Tinto, etc.), and many others. Their contributions and support are thankfully acknowledged. The authors also would like to thank Dr. E. Hoek for providing access to his extensive triaxial test data base. 


\section{References}

Bieniawski, Z.T. (1989) Engineering Rock Mass Classification, Wiley, New York.

Cai, M., Kaiser, P.K., Tasaka, Y. and Minami, M. (2006) Determination of residual strength parameters of jointed rock masses using GSI system, International Journal of Rock Mechanics and Mining Sciences, 44(2), pp. 247-265.

Corkum, A.G. and Martin, C.D. (2004) Analysis of a rock slide stabilized with a toe-berm: a case study in British Columbia, Canada, International Journal of Rock Mechanics and Mining Sciences, 41(7), pp. 1109-1121.

Diederichs, M.S., Carvalho, J.L. and Carter, T.G. (2007) A modified approach for prediction of strength and post yield behaviour for high GSI rock masses in strong, brittle ground, 1st Canada-U.S. Rock Mech. Symposium, pp. 249-257.

Diederichs, M.S., Kaiser, P.K. and Eberhard, K.E. (2004) Damage initiation and propagation in hard rock and influence of tunnelling induced stress rotation, International Journal of Rock Mechanics and Mining Sciences. 41, pp. $785-812$.

Diederichs, M.S. (2003) Rock fracture and collapse under low confinement conditions, Rocha Medal Recipient, Rock Mechanics and Rock Engineering., 36(5), pp. 339-381.

Einstein, H.H. (1996) Tunnelling in difficult Rock - swelling behaviour and identification of swelling rocks, Rock Mechanics and Rock Engineering, 29(3), pp. 113-124; see also: Einstein, HH.; Bischoff, N. und Hofmann E. (1972). Das Verhalten von Stollensohlen in quellendem Mergel. Untertagbau Symposium, Luzern, pp. 296-312.

Grob, H. (1972) Schwelldruck im Belchentunnel, Internationales Symposium für Untertagbau, Luzern, pp. 99-109.

Hoek, E. (2007) Practical Rock Engineering, 2nd Edition. Rocscience Inc.

Hoek, E. and Bray, J.W. (1981) Rock Slope Engineering, London: Institution of Minerals and Metals.

Hoek, E. (1968) Brittle Failure of Rock, In Rock Mechanics and Engineering Practice, John Wiley and Sons Ltd. London, pp. 99-124.

Martin, C.D. and Maybee, W.G. (2000) The strength of hard-rock pillars. International Journal of Rock Mechanics and Mining Sciences, 37(8), pp. 1239-1246.

Martin, C.D., McCreath, D.R. and Maybee, W.G. (2000) Design approaches for hard-rock pillars, 53rd Canadian Geotechnical Conference, Bitech Publishers Ltd., Richmond 1, pp. 291-298.

Martin, C.D., Kaiser, P.K. and McCreath, D.R. (1999) Hoek-Brown parameters for predicting the depth of brittle failure around tunnels, Canadian Geotechnical Journal, 36(1), pp. 136-151.

Martin, D. (1997) The effect of cohesionloss and stress path on brittle rock strength. Canadian Geotechnical Journal, 34, pp. 698-725.

Morgenstern, N.R. and Price, V.E. (1965) The analysis of the stability of general slip surfaces, Geotechnique 15(1), pp. 79-93.

Kaiser, P.K. (2007) Rock mechanics challenges and opportunities in underground construction and mining, Keynote lecture, 1st Canada-U.S. Rock Mechanics Symposium, on CD, 47 p.

Kaiser, P.K. (2006) Rock mechanics consideration for construction of deep tunnel in brittle ground, Keynote lecture, Asia Rock Mechanics Symposium, Singapore, 12 p., on CD.

Kaiser, P.K., Vasak, P. and Suorineni, F.T. and Thibodeau, D. (2005) New dimensions in seismic data interpretation with 3-D virtual reality visualization in burst-prone grounds. Keynote Address to 6th RaSiM6, Perth, Australia, 33-47.

Kaiser, P.K. (2006) Tunnel stability in highly stressed, brittle ground - Rock mechanics considerations for Alpine tunnelling, Geologie und Geotechnik der Basistunnels, Keynote lecture at GEAT'05 Symposium, Zürich, Switzerland, pp. 183-201.

Kaiser, P.K., Diederichs, M.S., Martin, C.D., Sharp, J. and Steiner, W. (2000) Underground works in hard rock tunnelling and mining, GeoEng 2000, Technomic Publ. Co., pp. 841-926.

Kaiser, P.K., McCreath, D.R. and Tannant, D.D. (1996) Canadian Rockburst Support Handbook, Mining Research Directorate, Sudbury, Canada, 314 p.; see also Drift support in burst-prone ground, CIM Bulletin, 89(998), pp. 131-138.

Sarma, S.K. (1979) Stability analysis of embankments and slopes, ASCE Journal of Geotechnical Engineering Division, 105(GT12), pp. 1511-1524.

Yong, S., Kaiser, P.K., Löw, S. and Corrado, F. (2008) The Role of heterogeneity on the development of excavationinduced fractures in the Opalinus Clay, Canadian Geotechnical Conference, Edmonton, 8 p. (in press). 